\title{
UNCERTAINTY OF PROPERTY VALUATION AS A SUBJECT OF ACADEMIC RESEARCH
}

\author{
Ewa Kucharska - Stasiak, prof., Ph.D. \\ Department of Investment and Real Estate \\ University of Lodz \\ e-mail:ewkuchar@uni.lodz.pl
}

\begin{abstract}
Property valuation is characterized by uncertainty, understood not only as uncertainty of a single valuation, but also as a discrepancy between multiple valuations of the same property carried out at the same time and for the same purpose. A valuation is only an estimate, the outcome of which depends on the assumptions adopted by the valuer. Such assumptions may account for the potential of a property in a complex market environment in different ways.

The objective of the paper is to present the methodology of research devoted to valuation uncertainty in highly developed markets to emphasize the need to conduct such research in Poland, and to indicate the areas in which professional organizations should undertake actions.
\end{abstract}

Keywords: valuation, uncertainty of valuation.

JEL Classification: R30.

Citation: Kucharska-Stasiak E., (2013), "Uncertainty of property valuation as a subject of academic research", Real Estate Management and Valuation, vol. 21, no. 4, pp. 17-25.

DOI: $10.2478 /$ remav-2013-0033.

\section{Introduction}

A valuation is a professional opinion on value formulated on the basis of the assumptions adopted. An important issue here is the degree of certainty that a given valuation reflects the market realities as well as the features and potential of the property, or that it corresponds to the price that would be obtained on the day of valuation in an arm's length transaction. Uncertainty of valuation may be regarded not only as uncertainty concerning a single valuation, but also as the difference between multiple valuations of the same property conducted at the same time and for the same purpose (see section 3.2).

Both appraisers and their clients would like to believe that the value given is a true value, which is a myth. Myths concerning valuation have been aptly debunked by A. Damodoran, one of the twelve most prominent business school professors in the USA, and an author of books on appraisal of securities and corporations. He observes that (DAMODORAN, 2006):

- valuation does not lead to true value because "all valuations are biased. The only questions are "how much" and 'in which direction.' The direction and magnitude of bias in your valuation is directly proportional to who pays you and how much you are paid,"

- valuation does not ensure an exact estimate of value as "there are no precise valuations."

The importance of the problem is also revealed by the guidelines stipulated in the British professional standards, in which one of the chapters is devoted to the uncertainty of valuation. It reads: "Valuation is not a fact; it is an estimate" (RICS Professional Standards). Thus, it is little wonder that uncertainty is the subject of research, especially in Great Britain and Australia ${ }^{1}$ (NEwELL,

${ }^{1}$ Ranking of research priorities was determined for funds investing in real estate; however, many of the issues in question are also relevant for other market actors. 
WORZALA, MCALLISTER, SCHULTE, 2004).

Research devoted to uncertainty is deeply rooted in economics, as it seeks to determine the degree of fallibility of market objectivization in the process of estimating market value, especially in the context of the real estate market, which is quite unique given the specific features of real properties (such as fixed location, long useful life, low liquidity) and of the market itself (low effectiveness, low elasticity of supply and demand). The behaviors of actors in this market lead to a higher imperfection of property valuations as compared to other assets.

Valuation uncertainty is perceived as a symptom of errors in valuation. Thus, research on uncertainty is crucial to the correct understanding of valuation reports and is of utmost importance not only for valuers (given their professional, civil, and penal liability), but also for their clients as the addressees of valuation reports.

Research into the problem of uncertainty is indicative of the emergence of new trends in valuation theory that aim to revise the notions rooted in the neo-classical theory of valuation and adopt a new perspective on them. To do so, the valuer will need to take into account the behavioral interactions of market actors in a market that exhibits extremely low efficiency and in which both parties to a transaction realize they can affect the price. In such a market, it is much more complicated to determine value than in markets with large numbers of transactions, where nobody can influence the price, and where the traded goods are highly uniform.

\section{Motivation for research}

The uncertainty of valuation is not given much scholarly attention in Poland. To date, only a few papers have been published that point to the need of undertaking research in this area ${ }^{2}$. The notion of the uncertainty of valuation is reluctantly acknowledged by practitioners, who associate it with a lack of professionalism and a risk of distrust on the part of their clients. Many Polish valuers, especially those with a technical education, believe that if they put their signature under a figure that is taken to represent the value of a property, then that figure must be absolutely reliable. They certainly do not understand that a real estate valuation is only an attempt at the objectivization of the market, which is quite imperfect ${ }^{3}$, because objectivization faces many difficulties. In economics, objectivization may never be complete. An important feature of economics as a social science is that the use of scientific methods of study is severely hampered - it would be difficult to isolate an economic phenomenon and reduce it to laboratory conditions, and moreover such phenomena are characterized by limited repeatability. Therefore, economic sciences make use of less precise methods, including surveys, tests, and observations. Imperfect objectivization is caused, first, by the need to assess the studied phenomena, and, second, by the researcher's attitude. Using observation as a method of study, the researcher gets to know only some features of assets and relations between those features. Some features and relations remain outside the researcher's observation capacity. Using the observation method carries the risk of error due to potentially superficial or biased observations (STACHAK, $2003 \mathrm{~s}$. 163). The possibility of error is linked to the observer's attitude - he or she may not be objective or may act in a routine way or in accordance with some presuppositions, which could lead to a selective choice of the observed facts, eliminating some facts that are not consistent with the presuppositions. The problem of the objectivization of economic phenomena in conjunction with behavioral reactions results in low valuation precision and in discrepancies between valuations.

Although it may be assumed that the above problems are inherent in the valuation process, an understanding of their underlying causes may help to partially neutralize them (where possible) and enable a different perspective on valuation figures. Thus, the issues of accuracy and uncertainty of valuation have both theoretical and practical implications, which confirms their importance. They are of particular significance in emerging markets, where objectivization seems to be more difficult to

\footnotetext{
${ }^{2}$ See: J. Adamiczka, Rola założeń i jakości danych w procesie szacowania a niepewność wyceny [The Role of assumptions and data quality in the valuation process and valuation uncertainty], Rzeczoznawca Majątkowy, 2005, Nr 3(47); E. Kucharska-Stasiak, Uncertainty of Valuation in the Emerging Markets: the Polish Case, European Real Estate Society Conference, Dublin 14-17 June 2005; E. Kucharska-Stasiak Niepewność wyceny w warunkach polskich [Uncertainty of valuation in Polish conditions], 14th National Conference of Property Valuers, Lublin 2005.

${ }^{3}$ For more see: E. Kucharska-Stasiak, Pomiar wartości na gruncie ekonomii - reperkusje dla wyceny nieruchomości [Measurement of value from the standpoint of economics - implications for property valuation], Studia i Materiały Towarzystwa Naukowego Nieruchomości, Volume 19, Number 1, Olsztyn 2011.
} 
achieve.

The aim of this paper is to present the methodology and results of research on the uncertainty of real estate valuation in developed markets, to identify the directions of study that should be undertaken by Polish academics, and to indicate the necessary actions to be taken by professional organizations.

\section{Uncertainty of valuation}

\subsection{Research problem}

The process of asset valuation seeks to objectivize the behaviors of transactors. However, actors in every market have their individual, subjective expectations as well as perceptions concerning the utility of a given asset. What is important for them is marginal utility, which represents additional benefits offered by a unit of a given good. For every person, this marginal utility may be different. Through the collective action of market actors, value ceases to be subjective and acquires an objective nature. Still, this objectivization is never perfect, and every asset valuation is burdened with some subjective elements. This means that from the standpoint of market objectivization, every valuation of an asset is fraught with uncertainty and is a source of risk.

Undoubtedly, uncertainty of property valuation is exceptionally high due to both the characteristics of real estate (e.g., variation in physical features, diversity of legal titles, high capital intensity) and the characteristics of the real estate market (e.g., lack of uniformity, very high imperfection, and low efficiency), as well as human behaviors. The level of uncertainty depends on the degree of market development in a given country, including the legal system (the collection of legal acts pertaining to property law; spatial planning), market transparency (e.g., lack of data or data ehich is difficult to access), and education of property valuers. The level of uncertainty rises during periods of high volatility in the real estate markets. It may also be increased due to pressure exerted by the clients.

Irrespective of the market development level, in the real estate market the client pays for a subjective interpretation of an objective scientific analysis and calculation (GILBERTSON, 2001). The more individualized the physical and legal characteristics of a property, the lower the market activity, the smaller its transparency, and the greater its immaturity, the more difficult the objectivization process becomes. Valuation reflects the quality of information and the manner of processing it. This means that the less mature the market is, the greater the uncertainty of valuation of an individual property, and also the larger the differences between multiple valuations of the same property may be. Thus, it seems that the degree of uncertainty is greater in emerging markets..

\subsection{Uncertainty as a subject of research}

The discussion on the uncertainty of valuation has been ongoing for several years, mostly inBritish literature. It was undoubtedly stimulated by the 1994 Mallinson Report, according to which values may differ depending on how valuers interpret the value-influencing factors (The Mallinson Report: Key Finding, 1994). The degree of uncertainty may vary depending on market conditions, but valuers should be able to quantify it. One of the recommendations was to develop universal professional standards for measuring and expressing the uncertainty of valuation. This recommendation was reiterated in the 2002 Carsberg Report (Property Valuation, The Carsberg Report, 1999).

According to Recommendation 15 of the Carsberg Report, a method should be established "by which uncertainty could be expressed in a manner which will be helpful and will not confuse users of the valuation. RICS should also seek to agree with appropriate representative bodies of those commissioning and using third party valuations the circumstances and format in which the valuer would convey uncertainty."

The ongoing discussion on the uncertainty of property valuation comprises several issues:

- the terminological issue pertaining to the definition of the uncertainty of valuation (uncertainty and risk of valuation);

- the methodological issue focused on finding measures of uncertainty and valuation risk;

- the application issue - how valuation outcomes should be interpreted and when they can be

\footnotetext{
${ }^{4}$ For more see: E. Kucharska- Stasiak, Uncertanity of Valuation In the Emerging Markets, the Polish Case, European Real Estate Society Conference,
} 
deemed reliable.

The application issue has been of primary importance, as the discussions undertaken were aimed at improving communication between the client and the valuer, facilitating the decision-making process for the client, and helping to make valuations more readily understandable by the users. It was decided that making the users aware of valuation uncertainty would improve the reliability and reputation of property valuers and, importantly, increase the utility of valuations (FRENCH, GABRIELLI, 2003).

\subsubsection{Terminological issue}

The term "uncertainty" emerged in discourse concerning risk. Various authors have sought to define risk in terms of economics, legal sciences, psychology, and statistics. The discussion has revealed considerable terminological confusion. Below are several interpretations of the term that may be useful in further analysis:

- risk is the objectivized uncertainty of the occurrence of an undesirable event,

- risk changes with uncertainty (WILLET, 1951),

- uncertainty denotes what is measurable, called risk, as well as true uncertainty, which is unmeasurable (KNIGHT, 1921),

- uncertainty is measured by the degree of belief. Risk is a state of the real world; uncertainty is a state of the mind (PFEFFER, 1956),

- risk and uncertainty are the same thing. They appear where there is more than one possible outcome. The greater the dispersion of possible outcomes, the greater the degree of uncertainty.

In terminological discussion concerning the valuation of real estate, most authors focus on uncertainty (FRENCH, 2007), while the notion of "the risk of valuation" as opposed to uncertainty is used less often (HUTCHINSON, ADAIR, LEHENY, 2004). It is deemed that uncertainty in valuation is a real and universal phenomenon (FRENCH, GABRIELLI, 2003).

Uncertainty may be considered as:

\section{a) Uncertainty of a single valuation}

The process of valuation takes place within the framework of economics, which means that the valuation outcome always depends on the adopted assumptions. The importance of this economic background is emphasized by the International Valuation Standards: "property valuers ... are those who deal with the special discipline of economics associated with preparing and reporting valuations (International Valuation Standards, 2005 s. 38). Given the above definitions, it seems that the uncertainty of a single valuation involves:

- a measurable part that may be called the risk of valuation,

- an immeasurable part that is expressed by the degree to which the transactors believe in the valuation outcome.

\section{b) Uncertainty understood as a discrepancy between multiple valuations}

This type of uncertainty arises when we are dealing with more than one outcome (SAMUELSON, MARKS, 1998). The uncertainty of a single valuation is connected to the uncertainty of input data, while uncertainty understood as a difference between one valuation and another concerns output data. These two areas are linked - the uncertainty of a single valuation is one of the sources of uncertainty understood as a discrepancy between different valuations.

The uncertainty of a single valuation, resulting from the uncertainty of the input data used for formulating it, may be considered:

- normal uncertainty in the valuation process, the underlying causes of which include:

$\circ$ an availability of market data for similar properties,

- an assessment of current and future market conditions,

- using particular data concerning the valuation of a given property, such as the capitalization rate, market rent, market expectations concerning increases in the rent, and the vacancy rate.

Every instance of introducing input data is accompanied by a certain degree of uncertainty.

- abnormal uncertainty, linked to the state of the market or some unique qualities of the property, such as a swimming pool in a detached house, or a very large cubic capacity, increase the uncertainty of the data used for valuation. The selection of data for valuation is not a 
mathematical exercise, but a heuristic process involving the ability to discover new facts and connections between market facts (FRENCH, GABRIELLI, 2003).

Uncertainty of valuation understood as a discrepancy between multiple valuations consists of:

- uncertainty of a single valuation (normal and abnormal);

- discrepancy resulting from different assumptions used for valuation and concerning, e.g., the manner of accounting for rental agreements (concluded for a limited period of time) at a level higher or lower than the current market value, the vacancy rate, the valuation models used, the manner of arriving at the yield, and the influence of the client on the valuation outcome ${ }^{5}$.

The potential influence of the client was emphasized in the Carsberg Report. In accordance with Recommendation 9 of the report, the Red Book should provide "specific guidance on the recording of occasions when a valuer discusses the outcome of the valuation with the client or any other interested party." Furthermore, Recommendation 10 suggests that "The RICS should set out, in the Red Book, standards of best practice and minimum requirements for the conduct and recording of draft valuation meetings designed to show what information was produced by the client which might influence the value derived, and how that information was used to influence, or otherwise, the final valuation figure. Rules for the disclosure of the record during monitoring should also be established." This shows that uncertainty does not only concern individual valuations, but also discrepancies between different valuations. Uncertainty concerning a discrepancy between different valuations is termed a margin of error (BROWN, MATYSIAK, 2000).

\subsubsection{Methodological issue}

In the studies conducted so far, an important problem was the method of measuring valuation uncertainty. For the uncertainty of individual valuations, the following methods have been proposed:

- Risk scoring (HUTCHINSON, ADAIR, LEHENY, 2004), - e.g., 1 for low risk and 4 for high risk. Apart from the great advantage of this method, which is its simplicity, it also has drawbacks, as it can lead to errors in the interpretation of market data and differentiate valuations into better and worse rather than characterized with higher or lower uncertainty.

- Standard deviation (FRENCH, MALLINSON, 2000), - the higher the uncertainty, the higher the standard deviation. Unfortunately, standard deviation shows deviation from the mean and assumes a normal distribution, which does not fit the processes that occur in the real estate market. Moreover, market actors are not likely to express uncertainty in terms of standard deviation.

- Coefficient of variation, or the ratio of standard deviation to the mean - is a measure of relative dispersion. The higher the coefficient the greater the uncertainty. Similarly to standard deviation, market actors are not likely to express uncertainty in the form of a variation coefficient.

- Triangular probability distribution based on three absolute values: the most probable, maximum, and minimum. As this manner of representation of uncertainty does not have to presuppose a normal distribution, it fits the real estate market and the thought processes of the market actors better. However, this method is believed to lead to greater, $\backslash$ overestimated discrepancies (FRENCH, 2007).

- The Monte Carlo model (FRENCH, GABRIELLI, 2003) - this method is used for modeling processes too complicated to be estimated by means of analytical methods. Here, input data is replaced with random figures within a defined probability distribution to determine subsequent output levels. Several thousand iterations need to be completed. When a property is valued using the capitalization approach, then two factors, rent and the capitalization rate, are used as input variables. Values are chosen at random, according to a known distribution. As normal distribution does not correspond to the behaviors or the market actors, the Monte Carlo method could be applied to a triangular probability distribution assuming three absolute values: the

\footnotetext{
5 Interestingly, according to one study " $79 \%$ of appraisers knew of instances of clients pressuring appraisers to alter their value estimates, with the most prevalently mentioned sources of client pressure being mortgage bankers and commercial banks." An important factor for valuers' decisions was the size of the entity represented by the client, as well as their professional experience. See M. L. Wolverton, Self-Perception of the Role of the Appraiser: Objective Opinions Or Price Validations?, The Appraisal Journal, July 2000.
} 
most probable, maximum, and minimum. The output data is expressed as the mean of all the obtained values. If there is more uncertainty in the input data, the output data will also be fraught with greater uncertainty. Thus, one can assume that a potential client should realize that, e.g., a value reported for a vacant property is characterized by greater uncertainty than a valuation for a property with tenants, for which rent had already been set (FRENCH, 2007).

In studying uncertainty understood as discrepancy between different valuations, there are two major methods:

- The first method uses regression analysis:

$$
X=\beta_{0}+\beta_{1} \times Y+u_{t}
$$

where $X$ and $Y$ are valuations of one property made by two independent valuers. If the valuation outcomes are similar, the constant term should approach 0 , and the slope should be equal to 1 . Both valuations should represent the same market conditions. If the slopes are different, this means that the valuers have processed the same market information differently.

- The second method uses variance as a measure of variation. Variance is the arithmetic mean of squared deviations of a feature from the expected value.

\subsubsection{Application issue}

In the context of the uncertainty of individual valuations, the important questions concerning application are:

- whether a valuation outcome should be given as a value expressed by a single figure or a range,

- what interpretation of the figure should be given to the client.

In valuations prepared for taxation, insurance, or collateral purposes, valuation outcomes must be given as single figures. According to the British standards, "Unless specifically requested, the expression of values within a stated range is not good practice. In most cases the valuer has to provide a single figure," (RICS Professional Standards, 2012, GN1). However, both from the point of view of valuation theory and practice, a single figure value is a myth. While it is thought that the valuation outcome should be reported as a single figure, a description should be developed to explain the uncertainty of the outcome, as the final figure does not reflect the uncertainty of input data (FRENCH, MALLINSON, 2000).

In relation to the uncertainty of valuation understood as a value range, there has been a discussion concerning a permissible difference between valuations, termed the margin of error. Actually, this range may be the subject of court decisions, and exceeding the margin of error may be deemed negligence in valuation. Courts of law did not accept price as proof of valuation validity, but value, stating that the price comes from a different period than the value (CROSBY, LAVERS, MURDOCH, 2011). The notion of the margin of error was first used by a British court in 1977, as the judge suggested that valuations should remain within acceptable brackets of $10 \%-15 \%$. The following year, another judge hearing a different case decided that valuations contain an element of speculation and suggested a permissible margin of error of up to $15 \%$, which could be higher only under exceptional circumstances. The magnitude of the accepted margin of error is decided by the nature of the property and the market situation. In valuations of residential properties, the accepted margin is less than 5\% but may be as high as $15 \%$ for very unusual properties or for valuations concerning not very active or highly volatile markets (CROSBY, LAVERS, MURDOCH, 2011).

Academic research has questioned the use of the term "margin of error" to describe the degree of negligence as it has been proven that there are no robust empirical foundations for the determination of such an error and it is inconsistent with the available evidence (BROWN, MATYSIAK, 2000). A valuation outcome may remain within the acceptable brackets even in a situation where the methods used are not correct. What is called the margin of error depends on the uncertainty inherent in every valuation. That is perhaps why, in 1992, another judge questioned the correctness of the previous two verdicts. He decided that true value is practically impossible to calculate. Instead, a good test for valuations should be to determine whether the valuers possessed adequate skills and acted with due diligence. Thus, the methods adopted by the valuer and the correctness of estimation should be assessed. Currently, British courts do not pay particular attention to the acceptable range, whether small or large; the professionalism of valuers is now measured in terms of the valuation methods and procedures they use and the input data they choose (ADAIR, DOWNIE, MCGREAL, VOS, 1996). 


\subsection{Results of studies on the uncertainty of valuation}

A number of studies and experiments have been conducted to examine the uncertainty of valuation understood as variation between valuations. They involved different valuers estimating the value of the same set of properties as well as questionnaires simulating the valuers' behavior in the process of valuation. The valuers had access to the same databases, but they selected market data on their own. In an experiment, they were given the same market data to conduct independent valuations of the same properties. The questionnaire revealed a number of behavioral scenarios showing the valuers' behaviors in terms of valuation methodology in areas that were not precisely regulated in the professional standards. Two of the studies were based on ex post analysis, based on previously carried out valuations. The third study was based on ex ante analysis, involving the valuers' statements as to how they would act in a given situation.

In the first study, 10 valuers carried out independent valuations for an office property and other commercial property. The difference between the lowest and highest value reported for the office building was $24 \%$, while for the commercial property it was as much as $45 \% 6$.

Another study on variation in valuation using regression analysis was conducted by Brown. Based on 26 properties valued in 1981-1984 by two independent valuers, he showed that while the values produced were not identical, the differences between them were small - the $\beta \_0$ was close to 0 , and $\beta \_1$ close to 1 . The calculated determination coefficient was high, amounting to $0.98-0.99$ for each year, which meant that valuations made by one valuer accounted for about $98 \%$ of variation in the valuations made by the other. Based on these results, Brown concluded that there was no bias and valuers did not make early value judgments prior to the valuation process (CROSBY, LAVERS, MURDOCH, 2011). In a sample consisting of 446 valuations, Hutchison et al. found deviations from the mean valuation exceeding $+/-20 \%$ in $10.5 \%$ valuations, while $65 \%$ of all valuations remained within a $+/-10 \%$ bracket (CROSBY, LAVERS, MURDOCH, 2011). As every property was valued by over ten valuers, this means that they did not imitate one another.

An particularly interesting experiment was conducted by Smit and Vos, who asked five highly reputable property valuers to estimate the value of two properties (an office building and an apartment building) (SMIT, VOS, 2003). They were given the same input data, such as market data, macroeconomic variables, and details of the valued assets. In their valuations they used two approaches: the capitalization method and the discounted cash flow method. The study showed that the same input data led to different outcomes - in the capitalization method the outcome spread was $7 \%$ for the apartment building and $8 \%$ for the office building. In the discounted cash flow method, the differences were even greater, amounting to $14 \%$ and $18 \%$, respectively. The authors aptly observed that variation may result not only from the choice of different market and macroeconomic data, but also from the selected income model (constant in the capitalization method and variable in the discounted cash flow method) and from the actual calculation process (e.g., the manner of incorporating exogenous data in the risk of obtaining an income). If the valuers had been asked to select input data on their own, the spread in valuations would have been even larger. The results suggest that from the standpoint of valuation uncertainty, the constant income model, which contains a smaller number of variables, is more advantageous. The authors stated that considerable discrepancies in the discounted cash flow method indicate "anchoring," that is that the data was adjusted to one's prior idea of a property's value, which would suggest a bias in the valuations.

In a study conducted by the questionnaire method, Havard showed the major role of methodology in generating uncertainty. He proved that some differences between valuation outcomes can be traced to different uses of valuation methodology in solving particular problems (HAVARD, 2000). His 2000 study involved 28 valuers specialized in appraising commercial properties. The objective of the study was to examine the valuers' behaviors in terms of the methodology applied and corrections made to account for the characteristics of the valued properties. The questionnaire concerned the behavior of valuers appraising a property let out under different terms: let out at the level of the market rent on the day of valuation for 15 years with the rent to be revised every 5 years, let out 2 years before at a rent lower than the market rent on the date of valuation, and let out 2 years before at a rent higher than the market rent. Havard showed that:

\footnotetext{
6 The study was conducted by Hager and Lord; as described in N. Crosby, A. Lavers, S. Murdoch, Property
} valuation accuracy and variation and the "margin of error". 
- The choice of income models and valuation methods was made freely within the income approach. In all simulations, $86 \%$ of the valuers used constant cash flows or cash flows that were periodically variable as a consequence of rental agreements being terminated, while only $14 \%$ used a model of variable income characterized by a considerable increase. In valuing a property let out at a rent lower than the market rent, $63 \%$ of the valuers used the so-called term and revision method, while $37 \%$ used the layer and hardcore method. The proportions were reversed if valuation was performed for a property let out at a rent higher than the market rent - in which case the layer and hardcore method clearly predominated.

- The yields differed, as did the manner of arriving at them. The respondents used the so-called balanced yield (the same during the term of the rental agreement and after its termination, but at a level higher than the current level) or different yields. The study showed that the yields were adjusted in a subjective way rather than supported with market evidence.

The study results show that some discrepancies between valuation outcomes will always exist. They give rise to random and systematic deviations. Random deviations arise not only due to differences in the adopted exogenous data, endogenous differences in assessing the potential of an asset, or differences at the computation stage, but also due to behaviors of the market actors, which are reflected in different choices concerning income models, valuation techniques, and yields. On the other hand, systematic deviations lead to persistent under- or overestimation of property value (e.g., under the influence of the client's expectations or because of being impressed by the asking price or previous value estimates). An important role in the emergence of these deviations is played by the anchoring effect - valuers remain under the influence of previous estimates and transaction prices. The anchoring effect leads to underestimated values in growing markets and overestimated values in declining markets. Ensuring that valuers have high qualifications and experience will not eliminate the problem of valuation uncertainty in terms of random deviations. However, one should seek to eliminate the systematic ones.

\section{Conclusions}

The above presentation shows that uncertainty of valuation constitutes a major subject of research in countries with mature real estate markets, where valuation has a more robust tradition than in Poland. It has also been demonstrated that the uncertainty of valuation depends on the degree of market maturity.

The issue of valuation uncertainty has very important practical implications. In markets where the phenomenon of uncertainty is not accepted as something real and universal in the process of valuation, the utility of a valuation for the client is low, which undermines the reliability and reputation of valuers. This is clearly shown in the British standards: "Valuers should not treat a statement expressing less confidence than usual in a valuation as an admission of weakness. Indeed, if a failure to draw attention to material uncertainty gives a client the impression that greater weight could be attached to the opinion than is warranted, the report would be misleading" (RICS Professional Standards, 2012). A lack of awareness of the uncertainty of an individual valuation and the related uncertainty understood as a discrepancy between different valuations is a source of conflicts between valuers and clients, and between valuers and institutions assessing valuation reports. Thus, relevant research should be undertaken in Poland involving both academics and practitioners. This research should give rise to such recommendations in the national valuation standards that would substantially limit valuation discrepancies. On the one hand, the standards should provide for the measurement and reporting of valuation uncertainty, especially abnormal uncertainty On the other hand, the standards should specify methodology in a more exact manner so that it could not be freely interpreted, thus limiting discrepancies arising from inconsistent assumptions concerning, e.g., the manner of accounting for rental agreements at a level higher or lower than the current market value, the vacancy rate, the valuation models used, the manner of arriving at the yield, and the influence of the client on the valuation outcome.

This kind of action of professional associations seems to be of particular relevance in Poland, not only because the market is immature, but also due to the fact that practitioners are under the influence of different schools of valuation: American, British, and German. Thus, a paramount role is to be played by the national valuation standards in improving the utility of valuation reports and the reliability of the property valuer profession. The need to undertake the research and actions indicated 
in this paper is not directed against property valuers; on the contrary, it is in their interest, and also in the interest of their clients.

\section{References}

Adair A., Downie M. L., MCGreal S., Vos G., 1996, European Valuation Practice, Theory and Techniques, E and FN Spon.

ADAMICZKA J., 2005, założeń i jakości danych w procesie szacowania niepewności wyceny, Rzeczoznawca Majątkowy, Nr 3(47).

Brown G. R., Matysiak G., 2000, Real Estate Investment. A Capital Market Approach, Financial Times, Prentice Hall.

Crosby N., LAVERS A. , Murdoch J., 2011, Property valuation accuracy and variation and the "margin of error", 11th European Real Estate Society, Eindhoven, The Netherlands, 2011.

DAmodoran A., 2006, Valuation Approaches and Metrics: A Survey of the Theory and Evidence, Stern School of Bisiness.

FISCHER D., 2004, Erroneous Errors In Valuation, ERES Conference, Milan.

French N., 2007, Valuation uncertainty. Common Proffesional Standards and Methods, 13th Pacific-Rim Real Estate Society Conference, Western Australia, 21 to 24 January 2007.

French N., MAllinson M., 2000, Uncertainty In Property Valuation. The Nature and Relevance of uncertainty and how it might be measured and reported, Journal of Property and Finance,Vol.18, No.1, 2000.

FRENCH N., GABRIELLI L., 2003, Valuation The Uncertainty of Valuation, ERES, Helsinki.

GILBERTSON. B., 2001, Valuation Valuation or Appraisal: Art or Science?, Global Real Estate Now, Spring 2001.

KNIGHT E. H., 1921, Risk, Uncertainty and Profit, University of Boston Press, Boston.

KUCHARSKA-STASIAK E., 2005, Uncertainty of Valuation In the Emerging Markets, the Polish Case, ERES, Dublin 14-17 June 2005.

KUCHARSKA-STASIAK E., 2005, Niepewność wyceny w warunkach polskich, XIV Krajowa Konferencja Rzeczoznawców Majątkowych, Lublin 2005.

HAVARD. T. M., (...),Variations In Methodologies In Commercial Investment Valuation, Oxford Brookes University.

Hutchinson N. E., AdAIR A. S., LeHENy A. S., 2004, The Reporting of Risk in Real Estate Appraisal: Property Risk Scoring, ERES Conference, Milan June 2004.

Newell G., WorZala E., MCAllister P., SCHUlte K., 2004, An international Perspective on Real Estate Research Priorities, Journal of Real Estate Portfolio Management, 2004, No. 3.

NubereIT P., 2008, The Harmonisation of Property Valuation, The Role of Valuation Parameters and Terminology, ERES.

Międzynarodowe Standardy Wyceny, 2005, (WYDANIE POLSKIE), PFSRM, Warszawa.

PFEFFER J., 1956, Insurance and Economic Theory, Irvin Inc., Homewood, Illionis.

Property Valuation, The Carsberg Report, 1999, RICS.

SAMUELSON W. F., MARKS S. G., 1998, Ekonomia menedżerska, PWE, Warszawa.

SMIT W. N. M. , Vos G A., 2003, In valuation: will idenctical data input lead to identical output of valuation results?, ERES Conference, Finland,

STACHAK S., 2003, Podstawy metodologii nauk ekonomicznych, KSIĄŻKA I WIEDZA,

Standardy Zawodowe RICS, 2012, Royal Institution of Chartered Surveyors.

The Mallinson Report: Key Finding, 1994, RICS.

Willet A. H., 1951, The Economic Theory of Risk Insurance, University of Pennsylvania, Press, Philadelphia.

Wolverton M. L., 2000, Self- Perception of the Role of the Appraiser: Objective Opinions Or Price Validations?, The Appraisal Journal, July 2000. 